\title{
Cephalometric oropharynx and oral cavity analysis in Chiari malformation Type I: a retrospective case-control study
}

\author{
Aintzane Urbizu, PhD, ${ }^{1,2}$ Alex Ferré, MD, ${ }^{3}$ Maria-Antonia Poca, MD, PhD, ${ }^{4}$ Alex Rovira, MD, ${ }^{5}$ \\ Juan Sahuquillo, MD, PhD, ${ }^{4}$ Bryn A. Martin, PhD, ${ }^{2}$ and Alfons Macaya, MD, PhD ${ }^{1}$ \\ ${ }^{1}$ Pediatric Neurology Research Group, Vall d'Hebron Research Institute; ${ }^{3}$ Sleep Unit, Department of Clinical Neurophysiology, \\ ${ }^{4}$ Department of Neurosurgery and Neurotraumatology and Neurosurgery Research Unit, and ${ }^{5}$ Magnetic Resonance Unit (IDI), \\ Department of Radiology, Vall d'Hebron University Hospital, Universitat Autònoma de Barcelona, Spain; and ${ }^{2}$ Conquer Chiari \\ Research Center, Department of Mechanical Engineering, The University of Akron, Ohio
}

\begin{abstract}
OBJECTIVE Traditionally, Chiari malformation Type I has been related to downward herniation of the cerebellar tonsils as a consequence of an underdeveloped posterior cranial fossa. Although the common symptoms of Chiari malformation Type I are occipital headaches, cervical pain, dizziness, paresthesia, and sensory loss, patients often report symptoms related to pharyngeal dysfunction such as choking, regurgitation, dysphagia, aspiration, chronic cough, and sleep disorders. In addition, tracheal intubation is often difficult in these patients. The purpose of this study was to analyze the morphological features of the oropharynx and oral cavity in patients with Chiari malformation Type I to help identify underlying anatomical anomalies leading to these debilitating symptoms.

METHODS Seventy-six adult patients with symptomatic Chiari malformation Type I with cerebellar tonsillar descent greater than $5 \mathrm{~mm}$ below the foramen magnum and a small posterior cranial fossa and 49 sex-matched controls were selected to perform a retrospective case-control MRI-based morphometric study in a tertiary hospital. Eleven linear and areal parameters of the oropharyngeal cavity on midsagittal T1-weighted MRI were measured and the average values between patients and control cohorts were compared. Correlations between variables showing or approaching statistical significance in these structures and posterior cranial fossa measurements related with the occipital bone were sought.
\end{abstract}

RESULTS Significant differences were detected for several oropharynx and oral cavity measures in the patient cohort, primarily involving the length and thickness of the soft palate ( $p=9.5 \mathrm{E}-05$ and $p=3.0 \mathrm{E}-03$, respectively). A statistically significant $(p<0.01)$ moderate correlation between some of these variables and posterior cranial fossa parameters was observed.

CONCLUSIONS The existence of structural oropharyngeal and oral cavity anomalies in patients with Chiari malformation Type I was confirmed, which may contribute to the frequent occurrence of respiratory and deglutitory complications and sleep disorders in this syndrome.

http://thejns.org/doi/abs/10.3171/2016.1.JNS151590

KEY WORDS oropharynx and oral cavity; Chiari malformation Type I; MRI; magnetic resonance imaging; soft palate

$\mathrm{C}$ HIARI malformation Type I (CMI) is a neurological disorder radiographically defined by low-lying cerebellar tonsils that descend at least $3-5 \mathrm{~mm}$ below the foramen magnum (FM). ${ }^{3}$ Several mechanisms producing the cerebellum tonsillar herniation have been described. ${ }^{22}$ Due to this heterogeneity in CMI pathophysiology, studies have started to focus on specific subtypes of patients with CMI, selected in accordance with the underlying mechanisms. This has emphasized the importance of an accurate characterization of the patients to better understand the disease. ${ }^{17,18,30}$
Experimental work ${ }^{16}$ and morphometric studies ${ }^{2,21,22,25}$ support that 1 factor leading to CMI is a small posterior cranial fossa (PCF) with a short occipital bone due to early paraxial mesodermal underdevelopment. Patients with tonsillar descent associated with PCF underdevelopment have been identified as having classic $\mathrm{CMI}^{22}$ and may present a complex clinical picture, with variable symptoms that occur in many combinations. Common CMI symptoms and related complications are occipital headaches, cervical pain, weakness, dizziness, paresthesia, sensory loss, motor weakness, syringomyelia, and hydrocephalus, which 
are thought to be related to direct compression of nervous tissue and CSF disturbances. Other manifestations such as aspiration, regurgitation, choking, dysphagia, abnormal vocal cord function, chronic cough, or sleep disorders are presumed to result from impaired oropharyngeal function or upper airway obstruction and are often neglected, despite being debilitating conditions that may even become life threatening. ${ }^{8,15}$

Surgical PCF reconstruction is the most effective treatment for CMI. However, intubation can be difficult in these patients and may increase risk for complications during surgical procedures. ${ }^{23}$ Studying and understanding the oropharyngeal and oral cavity defects may help neurosurgeons and anesthesiologists to use a better approach for endotracheal intubation and PCF decompression.

The aim of this study was to analyze the largely unrecognized CMI secondary defects of the facial skeleton (viscerocranium) and subsequent anomalies of the nasal, oral cavity, pharyngeal, and laryngeal regions by performing an MRI-based morphometric study in a cohort of adult patients with classic CMI that was compared with a control group. To this end, we used the mathematical model proposed by Urbizu et al. to discern those patients with CMI with a reduced PCF, with $93 \%$ sensitivity and $92 \%$ specificity. ${ }^{29}$ Given that all of these patients have in common a hypoplastic PCF, we also investigated whether these oropharynx alterations could be related to any of the altered PCF structures.

\section{Methods \\ Ethical Considerations}

All patients with CMI provided written informed consent prior to participation in the study. Control subjects were selected by the radiology service and were anonymized before their data were transferred to the research team. This study was approved by the institutional review board of Vall d'Hebron University Hospital of Barcelona.

\section{Subject Recruitment}

We selected 76 consecutive symptomatic adult patients who were evaluated at the Department of Neurosurgery, Vall d'Hebron University Hospital of Barcelona during the period 2004-2010 by 2 of the investigators (M.A.P. and J.S.) and who were diagnosed with congenital CMI after undergoing a cranial and spinal MRI study. Inclusion criteria were: 1) observation of tonsillar descent $>5$ mm below the FM on midsagittal T1-weighted MRI, and 2) patients with classic CMI. To verify the presence of the hypoplastic PCF, we used the mathematical model previously described by Urbizu and colleagues ${ }^{29}$ based on 7 PCF morphometric variables (distance from FM to corpus callosum, distance from FM to pons, Wackenheim angle, basal angle, osseous PCF area, basilar impression, and clivus length), where any result above the cutoff value of 0.55 classifies the PCF as hypoplastic.

This group included 47 women; the mean age of all patients was $42.1 \pm 12.2$ years (range 20-71 years). The most frequent signs and symptoms are depicted in Table 1. Patients had been symptomatic for a median period of 7 years prior to diagnosis. The most common symptom in this cohort was headache $(69 \%)$, which often featured neck pain (48\% of those with headache). Symptoms potentially related to oropharyngeal dysfunction included dysphagia (24\%), swallowing difficulties (17\%), dysphonia $(10 \%)$, and sleep disorders (49\%). Other associated findings were syringomyelia (53\%), hydrocephalus (29\%), basilar impression (5\%), retrocurved odontoid (12\%), and neurofibromatosis Type $1(18 \%)$.

The control group was composed of 49 individuals (30 women; the mean age of all patients was $35.2 \pm 6.8$ years) who underwent brain MRI after presenting with a clinically isolated syndrome suggestive of multiple sclerosis, and who were presumed to reflect the normal population in terms of PCF (none of these subjects showed tonsillar herniation $\geq 3 \mathrm{~mm}$ ) and oropharynx morphology.

\section{Morphological Measurements}

The MRI data were acquired using a 1.5-T scanner (MAGNETOM Symphony or MAGNETOM Vision, Siemens) equipped with a circular polarized receiver head array coil. In all patients and controls, a sagittal, conventional spin-echo T1-weighted sequence was obtained (TR 450-600 msec, TE 12-20 msec, acquisitions 2). The sequence was obtained with 4- to 5-mm slice thickness and $0.1-0.3$ interslice gap with a 144-256 × 256-384 imaging matrix, and $196 \times 230-$ mm FOV. Oral cavity and pharynx MR images of all patients and controls were analyzed using the digital picture archiving and communication system (PACS) on a NUMARIS/4 syngo postprocessing workstation, version MR 2004A (Siemens).

To evaluate the oropharynx morphometry, the following 11 measurements of the oropharynx and oral cavity, including linear and surface parameters, were performed on the midsagittal T1-weighted image for each subject (Fig. 1).

\section{Oral Cavity Area}

The oral cavity area was estimated as the surface delimited by the following boundaries: tip of the central incisor, a line following the maxilla and soft palate, epiglottis, vallecula, the most anterior and superior point on the body of the hyoid bone (representing the inferior part of the tongue), base of tongue, and genial tubercle (representing the most posterior point of the mandibular symphysis and the anteroinferior part of the tongue).

\section{Tongue Area}

The tongue area was estimated following the contour of the tongue where the boundaries are defined by the following points: tip of the tongue, vallecula, the most anterior and superior point on the body of the hyoid bone, and genial tubercle. ${ }^{27}$

\section{Tongue Length}

The tongue length was defined as a straight line running from the tip of the tongue to the vallecula. ${ }^{27}$

\section{Anterior-Posterior Pharyngeal Cavity Diameter}

The anterior-posterior pharyngeal cavity diameter was considered to be a straight line from the upper central incisor to the posterior pharyngeal wall, at the level of the tip of the epiglottis. 
TABLE 1. Clinical findings in 76 patients with classic CMI

\begin{tabular}{|c|c|}
\hline Variable & No. $(\%)^{*}$ \\
\hline No. of patients & 76 \\
\hline Sex, M/F & $29: 47$ \\
\hline Mean age in yrs $\pm S D$ & $42.1 \pm 12.2$ \\
\hline Mean age at diagnosis in yrs $\pm \mathrm{SD}$ & $35.7 \pm 11.8 / 73$ \\
\hline Hydrosyringomyelia & $39 / 73(53.4)$ \\
\hline Hydrocephalus & $21 / 73(28.8)$ \\
\hline Neurofibromatosis Type 1 & $13 / 73(17.8)$ \\
\hline Retrocurved odontoid & $8 / 65(12.3)$ \\
\hline Basilar impression & $4 / 73(5.5)$ \\
\hline Complex craniocervical malformation & $4 / 73(5.5)$ \\
\hline Pseudotumor cerebri & $2 / 73(2.7)$ \\
\hline Klippel-Feil malformation & $1 / 73(1.4)$ \\
\hline Platybasia & $1 / 73(1.4)$ \\
\hline \multicolumn{2}{|l|}{ Signs \& symptoms } \\
\hline Mean time elapsed from onset in mos \pm SD & $80.6 \pm 76.9 / 71$ \\
\hline Headache & $48 / 70(68.6)$ \\
\hline Occipital headache/cervicalgia & $33 / 68(48.5)$ \\
\hline Sleep disorders (RDI) & $18 / 37(48.6)$ \\
\hline Paresthesia upper limbs & $34 / 72(47.2)$ \\
\hline Cough, headache & $31 / 71(43.7)$ \\
\hline Sensory loss & $29 / 71(40.8)$ \\
\hline Neck pain & $27 / 72(37.5)$ \\
\hline Dizziness & $27 / 72(37.5)$ \\
\hline Motor weakness & $23 / 72(31.9)$ \\
\hline Instability & $21 / 71(29.6)$ \\
\hline Dysphagia & $17 / 72(23.6)$ \\
\hline Kyphoscoliosis & $11 / 50(22.0)$ \\
\hline Depression & $13 / 71(18.3)$ \\
\hline Upper limb pain & $13 / 72(18.0)$ \\
\hline Anxiety & $12 / 69(17.4)$ \\
\hline Difficulty swallowing & $12 / 72(16.7)$ \\
\hline Gait disturbances & $11 / 72(15.3)$ \\
\hline Paresthesia lower limbs & $11 / 72(15.3)$ \\
\hline Nystagmus & $8 / 54(14.8)$ \\
\hline Fatigue & $10 / 70(14.3)$ \\
\hline Visual alterations & $8 / 72(11.1)$ \\
\hline Dysphonia & $7 / 72(9.7)$ \\
\hline Lower limb pain & $5 / 72(6.9)$ \\
\hline Vertigo & $5 / 72(6.9)$ \\
\hline \multicolumn{2}{|l|}{ Therapeutic procedure } \\
\hline Surgical treatment & $42 / 73(57.5)$ \\
\hline
\end{tabular}

$\mathrm{RDI}=$ respiratory disturbance index.

* The figure after the slash indicates, for each variable, the number of subjects for whom information was available.

\section{Vertical Airway Length}

The vertical airway length was considered to reflect the length of the pharyngeal cavity and was defined as a line from the posterior nasal spine to the vallecula. ${ }^{20}$
Length of Soft Palate

The length of the soft palate was the distance from the posterior nasal spine to the uvula. ${ }^{27}$

\section{Thickness of Soft Palate}

The thickness of the soft palate was calculated on a line measuring the maximal thickness of the soft palate drawn perpendicular to the posterior nasal spine-uvula line. ${ }^{27}$

\section{Narrowest Upper Pharyngeal Airway Diameter}

The narrowest postpalatal airway diameter was a distance measured on a perpendicular line running from the uvula to the posterior pharyngeal wall line. ${ }^{27}$

\section{Narrowest Middle Pharyngeal Airway Diameter}

The narrowest middle pharyngeal airway diameter was measured as a perpendicular line from the most external point of the outline of the tongue to the posterior pharyngeal wall. ${ }^{19}$

\section{Narrowest Lower Pharyngeal Airway Diameter}

The narrowest lower pharyngeal airway diameter was estimated with a perpendicular line running from the most external point of the epiglottis to the posterior pharyngeal wall.

\section{Level of Epiglottis}

The level of epiglottis was considered to be the vertical distance from the tip of the epiglottis to the base of the odontoid process. The epiglottis and the odontoid process levels were established based on lines running from these structures to the posterior pharyngeal wall.

In addition, 7 PCF measurements related to occipital bone (supraoccipital length, anteroposterior diameter of FM, clivus length, osseous PCF area, anteroposterior diameter of PCF, basal angulation, and the Wackenheim angle) and 6 PCF measurements related to CNS anatomy (distance from the FM to the corpus callosum, fastigium, and pons; PCF area; PCF height; and tonsillar descent) were also measured in patients as previously described ${ }^{29}$ (Fig. 1) to study their possible correlation with the oropharynx measures that are significantly abnormal in patients with classic CMI.

Cephalometric analysis was performed by a single observer blinded to the clinical diagnosis. To evaluate intraobserver agreement for each morphometric method, we performed 2-way mixed intraclass correlation coefficients $(95 \% \mathrm{CI})$ on repeated measures for all measurements in 15 randomly selected control subjects and patients. A high intraobserver reliability was found (coefficient $>0.7$, range $0.69-0.99 ; \mathrm{p}<0.01)$.

\section{Statistical Analysis}

Statistical analyses of data are presented as percentages for categorical variables and mean values with their SDs for continuous variables. Parametric (ANOVA) or nonparametric (Mann-Whitney U) tests were used to compare: 1) continuous oropharynx and oral cavity variables between patient and control groups, and 2) altered oropharynx and oral cavity variables between patients with and without oropharynx symptoms. Parametric (Pearson) and nonparametric (Spearman's rho) correlations were 

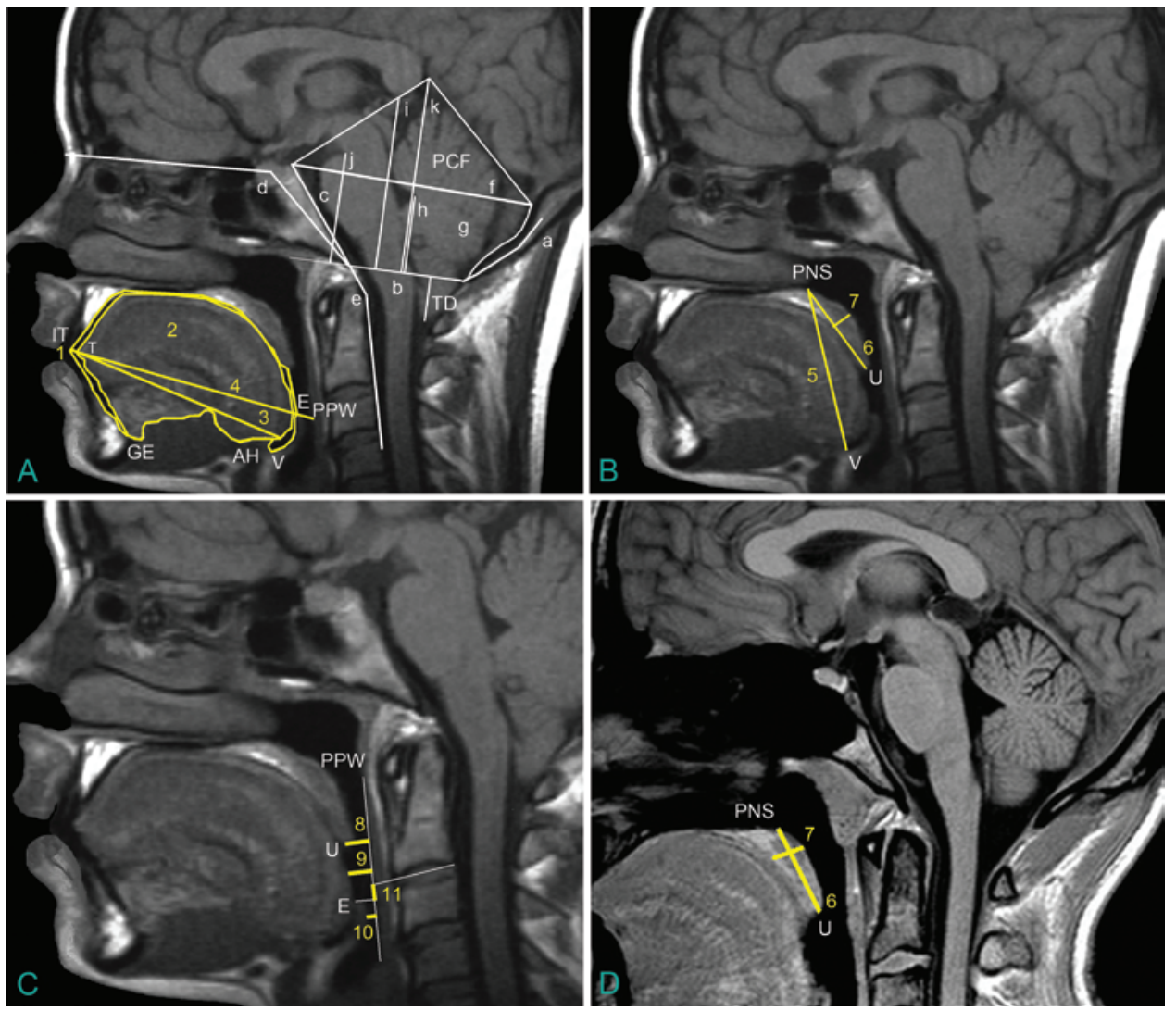

FIG. 1. Midsagittal T1-weighted MR images show the cephalometric measurements performed in this study in a CMI case (A-C) and the most significantly different parameters in a control case (D). A: White lines: Tonsillar descent (TD) and hypoplastic PCF were used as the inclusion criteria. Supraoccipital (a), anteroposterior diameter of FM (b), clivus length (c), basal angulation (d), Wackenheim angle (e), anteroposterior diameter of PCF $(f)$, osseous PCF area $(g)$, distance from FM to fastigium $(h)$, distance from FM to pons $(i)$, distance from FM to corpus callosum $(j)$, and PCF height $(k)$ were used as PCF measurements. Yellow lines: the oral cavity area (1) was estimated as the polygon delimited by the central incisor (IT), maxilla, soft palate, epiglottis tip (E), vallecula (V), the most anterior and superior point on the body of the hyoid bone (AH), base of tongue, and the genial tubercle; the tongue area (2) was inferred from a surface delimited by tip of the tongue (T), vallecula, hyoid bone, and genial eminence (GE); the tongue length (3) was inferred from a line running from tip of the tongue to vallecula; and the anterior-posterior pharyngeal cavity diameter (4) from a line from central incisor to posterior pharyngeal wall (PPW) at the level of the tip of the epiglottis. B: The vertical airway length (5) was estimated as the distance from the posterior nasal spine (PNS) to vallecula. Soft palate measurements: length (6) from posterior nasal spine to uvula (U) and thickness (7) as the length of perpendicular line to posterior nasal spine-uvula line. C: Pharyngeal airway diameter: upper (8) from uvula to PPW, middle (9) from the most external point of tongue to PPW, and lower (10) from epiglottis tip to PPW; level of epiglottis tip (11) estimated as a distance from epiglottis tip to the base of the odontoid process. D: Length (6) and thickness (7) of the soft palate in a control subject. Panels A, B, C, and D modified from Urbizu et al: MRI-based morphometric analysis of posterior cranial fossa in the diagnosis of Chiari malformation type I. J Neuroimaging 24:250-256, 2014. Used with permission. Figure is available in color online only.

used to study if the altered parameters of the oropharynx and oral cavity structures could be related to the reduced PCF in the patient cohort. Principal component analysis was performed to assess if the most altered oropharynx and oral cavity parameters could be directly related to the incidence of oropharynx symptoms reported by patients.

All tests were 2-tailed and the level of statistical significance was initially set at $p<0.05$. In the comparison analysis, the significant threshold was modified to $p<0.0045$ after applying the Bonferroni correction for multiple comparisons. Statistical analysis was performed using SPSS 17.0 (SPSS, Inc.).

\section{Results}

Table 2 shows the average values of the 11 oral cavity and oropharynx measurements performed in both cohorts. After applying the most conservative statistical correc- tion in the oropharynx and oral cavity analysis, patients showed statistically significant differences $(\mathrm{p}<0.0045)$ with respect to controls in 2 measures. The soft palate was longer and thinner in patients compared with control subjects (Fig. 2). We also observed a marked reduction in the oral cavity area and an epiglottal level that was lower and below the base of the odontoid process in patients $(\mathrm{p}<$ 0.05 ). However, we did not observe statistically significant differences in the diameter or the length of the pharyngeal cavity (taken as a measure of the vertical airway length) or in the pharyngeal airway diameters at their narrowest points.

The correlation analysis performed between the altered oropharynx measured variables and the PCF parameters (selected to reflect the anatomy of the occipital bone and posterior fossa content) in the 76 patients with classic CMI produced statistically significant results $(\mathrm{p}<0.01)$ (Table 3 ). Moderate positive correlations were observed between 
the oral cavity area and the anteroposterior diameter of PCF $(r=0.6)$; clivus length $(r=0.5)$; osseous PCF area $(r$ $=0.4)$; PCF area $(r=0.4)$; the anteroposterior diameter of FM, distance from FM to corpus callosum, and distance from FM to fastigium ( $r=0.3$ for all 3 ); and between the length of the soft palate and the osseous PCF area $(r=0.3)$. In addition, a moderate negative correlation was observed between the thickness of the soft palate and the Wackenheim angle $(r=-0.3)$ and between the level of epiglottis and distance from FM to corpus callosum $(r=-0.5)$, distance from FM to pons $(\mathrm{r}=-0.4)$, and PCF height $(\mathrm{r}=$ $-0.4)$.

None of the oropharynx measurements showed significant differences when the patients with CMI with and without oropharyngeal symptoms (dysphonia, dysphagia, and sleep apnea) were compared. Only the length of the soft palate approached but fell short of significance $(\mathrm{p}=$ 0.072 ), being longer in patients with CMI with oropharynx symptoms (results not shown). The PCA based on measurements related to the soft palate suggested a certain degree of separation between the CMI cohorts with and without symptoms, with the soft palate length being the main explanatory parameter (accounting for $66.5 \%$ of the global variance; Fig. 3).

\section{Discussion \\ Posterior Cranial Fossa and Oropharynx and Oral Cavity in $\mathrm{CMI}$}

Chiari malformation Type I is a disorder typically characterized by hindbrain overcrowding into an underdeveloped PCF due to a hypoplastic basioccipital bone. ${ }^{2,14,21,24,29}$ The majority of morphometric studies performed in CMI have focused on measuring different PCF parameters to demonstrate this mechanism as the cause of the tonsillar herniation. In contrast with these craniospinal adult CMI morphometric studies, the present study was only performed in adult patients with classic CMI. Furthermore, it was focused on the anatomy of the oropharynx and oral cavity to improve the characterization of these patients with classic CMI and to help understand symptoms and complications related to upper airway obstruction that are often encountered in these cases.

The retrospective analysis of 76 adult patients with classic CMI and 49 control subjects provided evidence that the oropharynx and oral cavity are also abnormal in these patients. Additionally, our results suggest that these abnormalities could be an anatomical adaptation as a consequence of an underdeveloped PCF. This is relevant as an additional mechanism accounting for the increased risk of secondary symptoms in CMI such as respiratory and deglutitory complications, sleep disorders, and also the occasional difficulties encountered during tracheal intubation. ${ }^{10,23}$

The occurrence of oropharyngeal difficulties is well known in Chiari malformation Type II. ${ }^{4-6,26}$ Although they have also been reported in CMI, ${ }^{21}$ they have received little attention and the scarce reports have mostly focused on pediatric cases. ${ }^{8,15}$ Tubbs and colleagues ${ }^{28}$ described a thinner midline superior pharyngeal constrictor muscle in 30 CMI pediatric patients with absent gag reflex using T1-weighted MR images; they suggested this alteration could be a possible cause of the oropharyngeal dysfunc-
TABLE 2. Cephalometric oropharynx analysis in patients and control subjects

\begin{tabular}{|c|c|c|c|}
\hline Variable & $\begin{array}{l}\text { Patients } \\
(n=76)^{*}\end{array}$ & $\begin{array}{l}\text { Controls } \\
(n=49)^{*}\end{array}$ & p Value \\
\hline Age (yrs) & $42.1 \pm 12.2$ & $35.2 \pm 6.8$ & - \\
\hline $\operatorname{Sex}(M / F)$ & $29: 47$ & $19: 30$ & - \\
\hline Tonsillar descent (mm) & $11.0 \pm 4.5$ & $-5.0 \pm 3.7$ & - \\
\hline Oral cavity area $\left(\mathrm{cm}^{2}\right)$ & $29.1 \pm 4.0$ & $30.7 \pm 3.8$ & 0.03 \\
\hline Tongue area $\left(\mathrm{cm}^{2}\right)$ & $26.8 \pm 3.7$ & $27.9 \pm 3.2$ & 0.09 \\
\hline Tongue length (mm) & $70.7 \pm 6.5$ & $69.6 \pm 5.5$ & 0.34 \\
\hline $\begin{array}{l}\text { Anterior-posterior pharyngeal } \\
\text { cavity diameter (mm) }\end{array}$ & $82.7 \pm 6.3$ & $83.0 \pm 6.3$ & 0.76 \\
\hline Vertical airway length $(\mathrm{mm})$ & $63.1 \pm 7.8$ & $62.1 \pm 6.9$ & 0.48 \\
\hline Length of soft palate (mm) & $36.0 \pm 4.8$ & $32.6 \pm 4.3$ & $9.5 \mathrm{E}-05$ \\
\hline Thickness of soft palate (mm) & $10.3 \pm 2.1$ & $11.4 \pm 1.7$ & $3.0 \mathrm{E}-03$ \\
\hline $\begin{array}{l}\text { Narrowest upper pharyngeal } \\
\text { airway diameter }(\mathrm{mm})\end{array}$ & $7.7 \pm 2.7$ & $7.7 \pm 2.3$ & 0.77 \\
\hline $\begin{array}{l}\text { Narrowest middle pharyngeal } \\
\text { airway diameter }(\mathrm{mm})\end{array}$ & $8.7 \pm 2.9$ & $9.4 \pm 3.1$ & 0.90 \\
\hline $\begin{array}{l}\text { Narrowest lower pharyngeal } \\
\text { airway diameter (mm) }\end{array}$ & $4.6 \pm 1.9$ & $4.8 \pm 2.3$ & 0.23 \\
\hline $\begin{array}{l}\text { Distance from tip of epiglottis } \\
\text { to odontoid base (mm) }\end{array}$ & $9.6 \pm 9.4$ & $6.3 \pm 7.5$ & 0.02 \\
\hline \multicolumn{4}{|c|}{$\begin{array}{l}\text { - }=\text { not applicable. } \\
\text { * Average values (mean } \pm \text { SD) are indicated for the } 11 \text { measurements. } \\
\dagger \text { Statistical significance was modified to } p<0.0045 \text { after applying the Bonfer } \\
\text { roni correction for multiple comparisons. }\end{array}$} \\
\hline
\end{tabular}

tion in these patients. In our study, we did not analyze the thickness of the posterior pharyngeal wall. However, we found additional alterations that could also explain the oropharyngeal dysfunction present in some adult patients with CMI.

The present results support previous work by MarínPadilla, ${ }^{15}$ showing that pediatric patients with CMI have a small oral cavity as well as a longer and compressed soft palate. However, the larger tongue size in patients with CMI observed by Marín-Padilla was not found in the present study. In addition, we did not observe elevation of the larynx or epiglottis. These differences could be explained by the morphological changes that occur in the pharynx between childhood and adult life. ${ }^{12}$ The presence of a thinner soft palate in the patient group could be attributed to the tongue pressure against the soft palate as a consequence of a reduced oral cavity, which may hinder the development of its full thickness and length. Indeed, our results indicate that the oral cavity area is the parameter more closely related to the PCF (osseous and neural structures), whereas the soft palate is related only to clivus length, osseous PCF area, and Wackenheim angle.

Conversely, the level of epiglottis relates to the parameters used to assess neural structures. Quite surprisingly, no correlation was observed between any of the oropharynx measures and the magnitude of tonsillar descent. The moderately significant correlations found between the altered parameters of the oropharynx and the parameters of the PCF related to the occipital bone (because the occipital hypoplasia is the main cause of shallow PCF) 

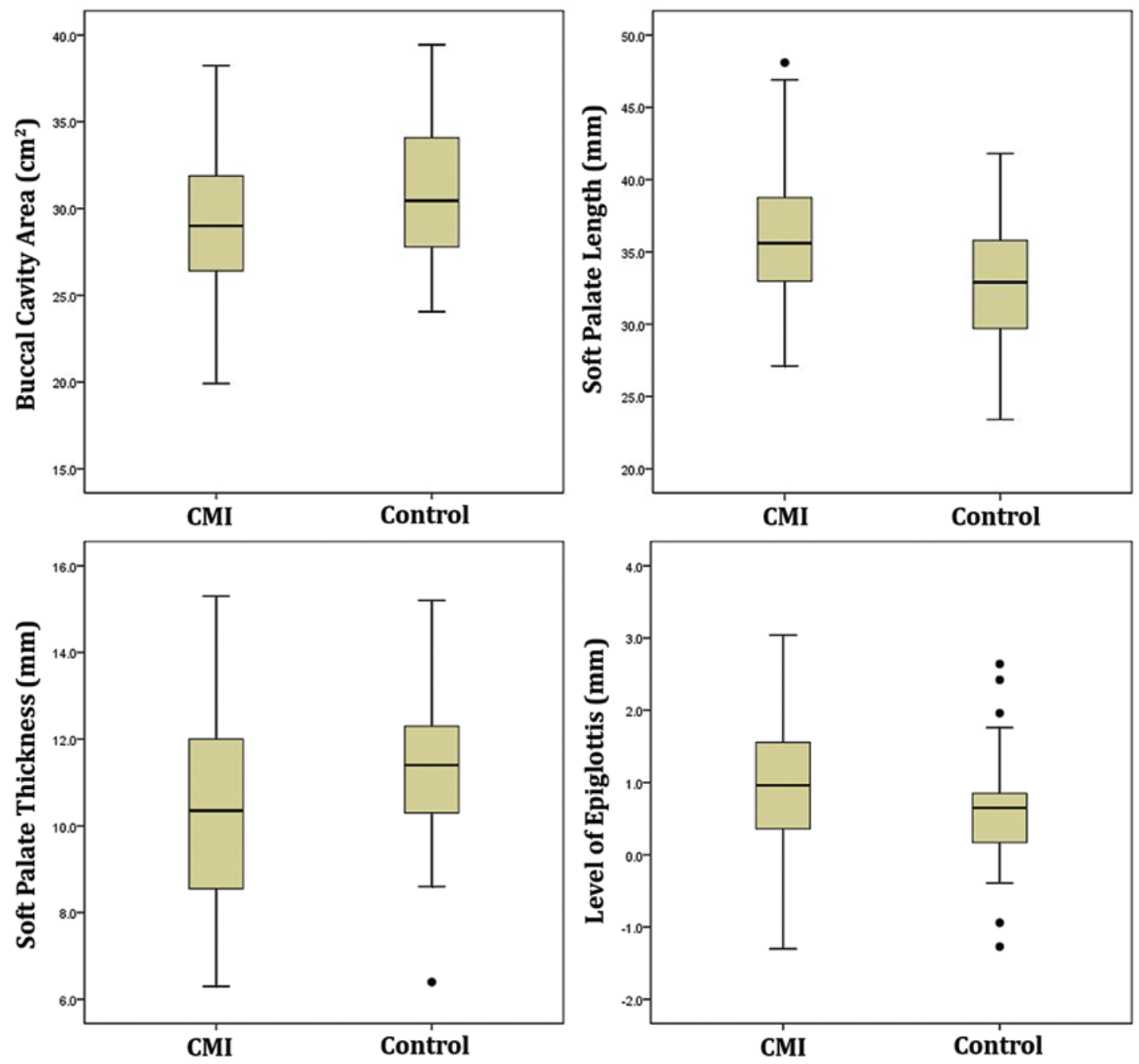

FIG. 2. Graphs showing the differences in oral cavity and oropharynx measurements between adult patients with CMI and control subjects. The box plots denote the ranges of the measurements with statistically significant differences: oral cavity area, soft palate length, soft palate thickness, and level of epiglottis. Boxes indicate \pm 1 SD and include the mean value (thick line); whiskers indicate \pm 2 SD. Dots depict subjects with measurements $>2 S D$. Figure is available in color online only.

(Table 3) could indicate, as suggested by Marín-Padilla, that oropharyngeal defects in Chiari malformations are secondary deformities that result from the adaptation of the facial skeleton to a primarily short and lordotic axial basicranium..$^{15}$

Craniofacial morphology is an important determinant of airway pathology.$^{19}$ It is known that an increase in the soft palate thickness and length predisposes individuals to partial or complete upper airway obstruction, and may be related to snoring duration or development of obstructive sleep apnea. ${ }^{1}$ Also, a lower larynx position may result in a longer collapsed segment of the upper airway and thus greater risk for obstructive sleep apnea. ${ }^{31}$ Sleep disorders and nocturnal respiratory abnormalities are frequent symptoms in patients with CMI. ${ }^{7}$ Although these can be produced by different neural dysfunctions, our findings suggest that an abnormal craniofacial structure may contribute to their occurrence in CMI. This is supported by the recent findings of Guerreiro et al., who described a smaller upper airway anteroposterior diameter in patients with CMI with sleep respiratory disorders. ${ }^{9}$
The anatomical features that predispose individuals to upper airway obstruction during sleep can also pose significant difficulties during the patient's intubation. ${ }^{11}$ The pharyngeal muscle tone that protects the airway is diminished both during sleep or anesthesia, as a result of decreased cortical influences and chemoreceptor drive, together with modulation of mechanoreceptor input. These changes may predispose an individual to partial or complete upper airway obstruction, particularly in those with already narrow and/or compliant upper airways. ${ }^{11}$ We did not observe changes in the upper airway diameter. However, if a long soft palate can indeed facilitate obstructive sleep apnea, then respiratory problems should also be expected during anesthesia.

On the other hand, dysphagia in patients with CMI has been reported to occur as a result of traction of the lower cranial nerves, secondary to the cerebellar herniation. ${ }^{28}$ However, because the soft palate serves as a mobile flap to prevent food and water from entering the nasal passages during swallowing, we also suggest that an elongated soft palate could be prone to hanging in front of the airway or 
TABLE 3. Correlation coefficients between the most significant morphometric differences found in the pharynx and PCF parameters in patients with classic CMI

\begin{tabular}{|c|c|c|c|c|}
\hline Variable & $\begin{array}{l}\text { Oral } \\
\text { Cavity } \\
\text { Area }\end{array}$ & $\begin{array}{l}\text { Length } \\
\text { of Soft } \\
\text { Palate }\end{array}$ & $\begin{array}{c}\text { Thickness } \\
\text { of Soft } \\
\text { Palate }\end{array}$ & $\begin{array}{l}\text { Level of } \\
\text { Epiglottis }\end{array}$ \\
\hline Supraoccipital length & 0.12 & $0.29^{*}$ & 0.19 & -0.00 \\
\hline $\begin{array}{l}\text { Anteroposterior diameter } \\
\text { FM }\end{array}$ & $0.31 \dagger$ & -0.08 & -0.10 & 0.05 \\
\hline Clivus length & $0.45 \dagger$ & 0.15 & $0.29^{*}$ & -0.15 \\
\hline Osseous PCF area & $0.36 \dagger$ & $0.30 \dagger$ & $0.29^{*}$ & -0.12 \\
\hline $\begin{array}{l}\text { Anteroposterior diameter } \\
\text { PCF }\end{array}$ & $0.57 \dagger$ & 0.01 & 0.15 & 0.14 \\
\hline Basal angulation & $-0.23^{*}$ & -0.15 & $-0.25^{*}$ & -0.00 \\
\hline Wackenheim angle & -0.06 & 0.02 & $-0.33^{*}$ & -0.24 \\
\hline Tonsillar descent & $-0.26^{*}$ & $-0.27^{*}$ & $-0.27^{*}$ & 0.04 \\
\hline PCF area & $0.39 \dagger$ & 0.17 & 0.20 & $-0.25^{*}$ \\
\hline PCF height & 0.16 & 0.15 & 0.07 & $-0.37 \dagger$ \\
\hline $\begin{array}{l}\text { Distance corpus cal- } \\
\text { losum to FM }\end{array}$ & $0.31 \dagger$ & 0.06 & 0.20 & $-0.46 \dagger$ \\
\hline Distance fastigium to FM & $0.32 \dagger$ & $0.26^{*}$ & 0.21 & $-0.23^{*}$ \\
\hline Distance pons to FM & $0.26^{*}$ & 0.12 & $0.23^{*}$ & $-0.36 \dagger$ \\
\hline
\end{tabular}

falling into the larynx during inhalation and producing the swallowing problems found in some patients with CMI.

Although soft palate abnormalities seemed to cluster in patients with symptomatic CMI (Fig. 3), we did not observe a statistically significant correlation between specific cephalometric measures and oropharynx-related symptoms. It should be noted, however, that this was a retrospective study where information on symptoms was not available for all of the subjects and it was based on subjective reports. Additional limitations were sample size and lack of sex matching (hence, interference of sex-related size differences cannot be ruled out). Prospective studies that include objective measures, such as polysomnography parameters, are needed to either prove or disprove our conclusions.

\section{Clinical Applicability of the Study}

Assessment of difficult airway function in patients begins with a comprehensive history and physical examination. Knowledge of the complications associated with the diagnosis of CMI can help anesthesiologists approach intubation cautiously and to be ready for long-blade laryngoscope or stylet use, or small-size endotracheal tubes, during the procedure.

\section{Strengths and Limitations of the Study}

In this retrospective study, we analyzed a relatively large and homogeneous cohort of patients: 76 symptomatic cases with a conservative definition of $\mathrm{CMI}$, tonsillar descent $>5 \mathrm{~mm}($ mean $=11 \mathrm{~mm})$, and documented PCF hypoplasia. Patient and control cohorts were selected with identical male/female ratios. Individuals younger than 18

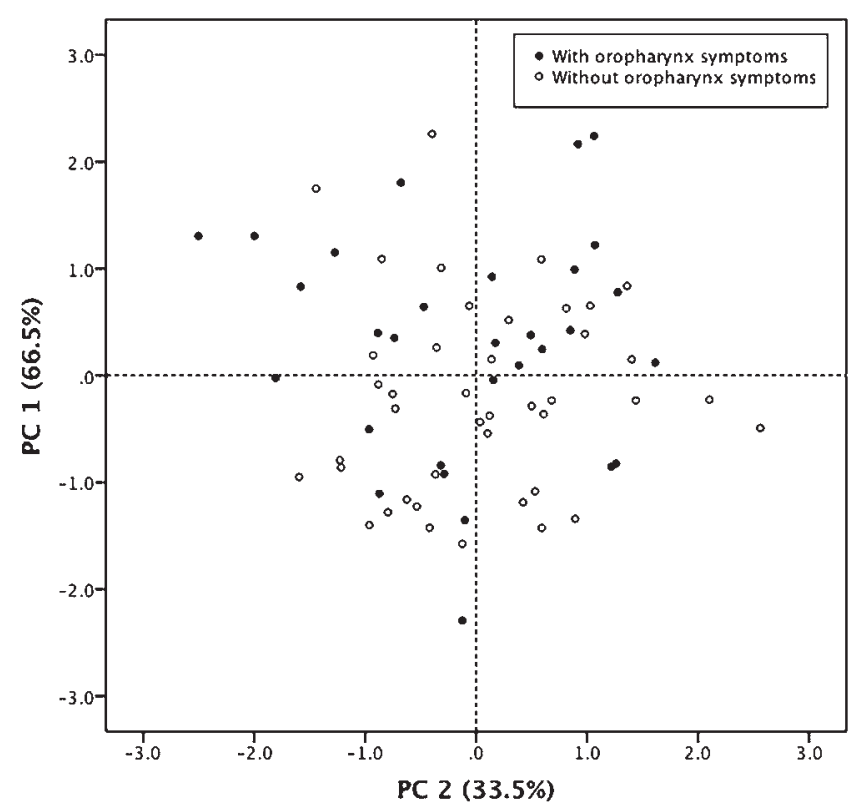

FIG. 3. Principal component (PC) analysis plot depicting the distribution of patients with CMI with and without oropharynx symptoms based on the significantly altered parameters of the oropharynx and oral cavity. PC1 $(66.5 \%$ of variance) was associated with the length of the soft palate, whereas PC2 (33.5\% of variance) was mainly explained by the thickness of the soft palate.

years were excluded to minimize age-related changes in the skull size and oropharyngeal structures. However, the mean age in the CMI and control groups was not matched (42.1 vs 35.2 years, respectively). Although soft oropharyngeal tissues could be altered with the age of the patient, ${ }^{13}$ we expect that these small age differences are not a factor underlying the differences found in the soft palate. On the other hand, a single midsagittal T1-weighted MRI slice was used for the morphometric measurements in the study. Slice orientation may not have been optimally placed at midsagittal plane, and small alterations in slice positioning could affect the measurements. Also, the tracheal diameter measurements were only obtained for the same single sagittal slice. Ideally, these measurements would be obtained by cutting orthogonally across the airway.

\section{Conclusions}

Adult patients with classic CMI were found to have several differences in the oropharynx and oral cavity morphology compared with a sex-matched control population. The most significant of these morphological differences was that patients with CMI had a longer and thinner soft palate; this factor may explain in part the respiratory complications, dysphagia, and swallowing problems that are often encountered in CMI. Prospective studies focused on objective pharyngeal functional measures will determine whether a correlation can be established between the altered structures we have identified and specific oropharyngeal symptomatology.

\section{Acknowledgments}

We thank Dr. Marín-Padilla, Professor Emeritus of Pathology 
and Professor Emeritus of Paediatrics, for the insightful discussion on CMI pathophysiology.

\section{References}

1. Akpinar ME, Celikoyar MM, Altundag A, Kocak I: The comparison of cephalometric characteristics in nonobese obstructive sleep apnea subjects and primary snorers cephalometric measures in nonobese OSA and primary snorers. Eur Arch Otorhinolaryngol 268:1053-1059, 2011

2. Aydin S, Hanimoglu H, Tanriverdi T, Yentur E, Kaynar MY: Chiari type I malformations in adults: a morphometric analysis of the posterior cranial fossa. Surg Neurol 64:237-241, 2005

3. Barkovich AJ, Wippold FJ, Sherman JL, Citrin CM: Significance of cerebellar tonsillar position on MR. AJNR Am J Neuroradiol 7:795-799, 1986

4. Bell WO, Charney EB, Bruce DA, Sutton LN, Schut L: Symptomatic Arnold-Chiari malformation: review of experience with 22 cases. J Neurosurg 66:812-816, 1987

5. Cai C, Oakes WJ: Hindbrain herniation syndromes: the Chiari malformations (I and II). Semin Pediatr Neurol 4:179191,1997

6. Choi SS, Tran LP, Zalzal GH: Airway abnormalities in patients with Arnold-Chiari malformation. Otolaryngol Head Neck Surg 121:720-724, 1999

7. Ferre Maso A, Poca MA, de la Calzada MD, Solana E, Romero Tomas O, Sahuquillo J: Sleep disturbance: a forgotten syndrome in patients with Chiari I malformation. Neurologia 29:294-304, 2014

8. Greenlee JD, Donovan KA, Hasan DM, Menezes AH: Chiari I malformation in the very young child: the spectrum of presentations and experience in 31 children under age 6 years. Pediatrics 110:1212-1219, 2002

9. Guerreiro RB, Bittencourt L, Reis RC, Rotta JM, Tufik S, Botelho RV: Upper airway dimensions in patients with craniocervical junction malformations with and without sleep apnea. A pilot case-control study. Arq Neuropsiquiatr 73:336-341, 2015

10. Hagberg C, Georgi R, Krier C: Complications of managing the airway. Best Pract Res Clin Anaesthesiol 19:641-659, 2005

11. Hillman DR, Platt PR, Eastwood PR: The upper airway during anaesthesia. Br J Anaesth 91:31-39, 2003

12. Infosino A: Pediatric upper airway and congenital anomalies. Anesthesiol Clin North America 20:747-766, 2002

13. Johnston CD, Richardson A: Cephalometric changes in adult pharyngeal morphology. Eur J Orthod 21:357-362, 1999

14. Karagöz F, Izgi N, Kapíjcíjoğlu Sencer S: Morphometric measurements of the cranium in patients with Chiari type I malformation and comparison with the normal population. Acta Neurochir (Wien) 144:165-171, 2002

15. Marín-Padilla M: Cephalic axial skeletal-neural dysraphic disorders: embryology and pathology. Can J Neurol Sci 18:153-169, 1991

16. Marin-Padilla M, Marin-Padilla TM: Morphogenesis of experimentally induced Arnold-Chiari malformation. J Neurol Sci 50:29-55, 1981

17. Markunas CA, Enterline DS, Dunlap K, Soldano K, Cope H, Stajich J, et al: Genetic evaluation and application of posterior cranial fossa traits as endophenotypes for Chiari type I malformation. Ann Hum Genet 78:1-12, 2014

18. Markunas CA, Lock E, Soldano K, Cope H, Ding CK, Enterline DS, et al: Identification of Chiari Type I Malformation subtypes using whole genome expression profiles and cranial base morphometrics. BMC Med Genomics 7:39, 2014

19. McNamara JA: Influence of respiratory pattern on craniofacial growth. Angle Orthod 51:269-300, 1981

20. Meredith GM: The airway and dentofacial development. Ear Nose Throat J 66:190-195, 1987

21. Milhorat TH, Chou MW, Trinidad EM, Kula RW, Mandell
M, Wolpert C, et al: Chiari I malformation redefined: clinical and radiographic findings for 364 symptomatic patients. Neurosurgery 44:1005-1017, 1999

22. Milhorat TH, Nishikawa M, Kula RW, Dlugacz YD: Mechanisms of cerebellar tonsil herniation in patients with Chiari malformations as guide to clinical management. Acta Neurochir (Wien) 152:1117-1127, 2010

23. Mustapha B, Chkoura K, Elhassani M, Ahtil R, Azendour H, Kamili ND: Difficult intubation in a parturient with syringomyelia and Arnold-Chiari malformation: Use of Airtraq laryngoscope. Saudi J Anaesth 5:419-422, 2011

24. Nishikawa M, Sakamoto H, Hakuba A, Nakanishi N, Inoue Y: Pathogenesis of Chiari malformation: a morphometric study of the posterior cranial fossa. J Neurosurg 86:40-47, 1997

25. Noudel R, Jovenin N, Eap C, Scherpereel B, Pierot L, Rousseaux P: Incidence of basioccipital hypoplasia in Chiari malformation type I: comparative morphometric study of the posterior cranial fossa. Clinical article. J Neurosurg 111:1046-1052, 2009

26. Papasozomenos S, Roessmann U: Respiratory distress and Arnold-Chiari malformation. Neurology 31:97-100, 1981

27. Sittitavornwong S, Waite PD, Shih AM, Koomullil R, Ito Y, Cheng GC, et al: Evaluation of obstructive sleep apnea syndrome by computational fluid dynamics. Semin Orthod 15:105-131, 2009

28. Tubbs RS, Webb D, Smyth MD, Oakes WJ: Magnetic resonance imaging evidence of posterior pharynx denervation in pediatric patients with Chiari I malformation and absent gag reflex. J Neurosurg 101 (1 Suppl):21-24, 2004

29. Urbizu A, Poca MA, Vidal X, Rovira A, Sahuquillo J, Macaya A: MRI-based morphometric analysis of posterior cranial fossa in the diagnosis of Chiari malformation type I. J Neuroimaging 24:250-256, 2014

30. Urbizu A, Toma C, Poca MA, Sahuquillo J, Cuenca-León E, Cormand B, et al: Chiari malformation type I: a case-control association study of 58 developmental genes. PLoS One 8:e57241, 2013

31. Yamashiro Y, Kryger M: Is laryngeal descent associated with increased risk for obstructive sleep apnea? Chest 141:14071413,2012

\section{Disclosures}

This work was supported by grants from Instituto de Salud Carlos III, Spain, grant PI061606; Fundació La Marató TV3, Spain, grant 062710; and Agència de Gestió d'Ajuts Universitaris i de Recerca (AGAUR), Spain, grant 2009SGR-0078. A.U. is the recipient of a Postdoctoral Fellowship from Fundación Ramón Areces (Spain). Conquer Chiari also supported this work.

\section{Author Contributions}

Conception and design: Macaya, Urbizu. Acquisition of data: Urbizu, Poca, Rovira, Sahuquillo. Analysis and interpretation of data: Urbizu. Drafting the article: Urbizu. Critically revising the article: all authors. Reviewed submitted version of manuscript: Urbizu. Approved the final version of the manuscript on behalf of all authors: Macaya. Statistical analysis: Urbizu. Study supervision: Macaya.

\section{Supplemental Information \\ Previous Presentations}

Portions of this paper were presented in poster form as proceedings at the Midwest meeting of the American Society of Biomechanics, Akron, OH, February 17, 2015.

\section{Correspondence}

Alfons Macaya, Grup de Recerca en Neurologia Pediàtrica, Vall d'Hebron Institut de Recerca, Pg Vall d'Hebron 119-129, 08035, Barcelona, Spain. email: amacaya@vhebron.net. 